\title{
H19 promotes endometrial cancer progression by modulating epithelial-mesenchymal transition
}

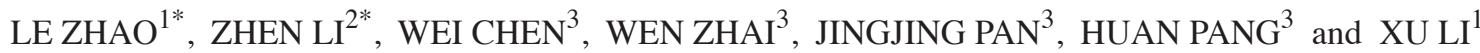 \\ ${ }^{1}$ Center for Translational Medicine; ${ }^{2}$ Department of Gynecology and Obstetrics; ${ }^{3}$ Center for Laboratory Medicine, \\ The First Affiliated Hospital, Xi'an Jiaotong University, Xi'an, Shaanxi 710061, P.R. China
}

Received July 1, 2015; Accepted October 7, 2016

DOI: $10.3892 / \mathrm{ol} .2016 .5389$

\begin{abstract}
Endometrial cancer is one of the most common types of gynecological malignancy worldwide. Novel biomarkers and therapeutic targets are imperative for improving patients' survival. Previous studies have suggested the long non-coding RNA H19 as a potential cancer biomarker. To investigate the role of H19 in endometrial cancer, the present study examined the expression pattern of $\mathrm{H} 19$ in endometrial cancer tissues by quantitative polymerase chain reaction, and characterized its function in the endometrial cancer cell line via knocking down its expression with small interfering RNAs. It was found that H19 level was significantly higher in tumor tissues than in paratumoral tissues. Knockdown of H19 did not affect the growth rate of HEC-1-B endometrial cancer cells, but significantly suppressed in vitro migration and invasion of HEC-1-B cells. Furthermore, H19 downregulation decreased Snail level and increased E-cadherin expression without affecting vimentin level, indicating partial reversion of epithelial-mesenchymal transition (EMT). The present findings suggested that H19 contributed to the aggressiveness of endometrial cancer by modulating EMT process.
\end{abstract}

\section{Introduction}

Endometrial cancer is the fifth most common type of cancer in females worldwide, accounting for $4.8 \%$ of all cancer cases in women (1). The incidence of endometrial cancer is higher in developed regions, such as North America and Northern and Western Europe than in Asia and Africa (2-4). However, the number of newly diagnosed cases of endometrial cancer have significantly increased between 2003 and 2013 in China (5).

Correspondence to: $\mathrm{Dr} \mathrm{Xu} \mathrm{Li}$, Center for Translational Medicine, The First Affiliated Hospital, Xi'an Jiaotong University, 277 West Yanta Road, Xi'an, Shaanxi 710061, P.R. China

E-mail: lixu56@mail.xjtu.edu.cn

\section{*Contributed equally}

Key words: H19, endometrial cancer, epithelial-mesenchymal transition
Endometrial cancer has been broadly classified into 2 groups based on histological examination $(6,7)$. Type 1 endometrial cancers are mainly adenocarcinomas of endometrioid origin, accounting for $70-80 \%$ of cases. Type 2 cancers are of non-endometrioid origin and classified as serous, clear cell and squamous cell cancers, accounting for $10-20 \%$ of all endometrial tumors. The prognosis of type 1 endometrial cancers is usually more favorable than type 2 cancers (8). In addition to tumor histology type, survival of endometrial cancer is strongly affected by tumor stage, grades, and invasive status. When diagnosed at advanced stages, or with poorly differentiated tumors, surgical treatment and chemotherapy are not curative for the two types of endometrial cancer patients, and 5 -year survival rate is poor. Novel biomarkers and therapeutic targets are therefore imperative for improving the survival of advanced endometrial cancer patients.

The H19 gene is located on chromosome 11p15.5 and is established as an imprinted gene $(9,10)$. The $\mathrm{H} 19$ gene encodes a spliced and polyadenylated RNA that lacks conserved open reading frames. Since no endogenous translation product has been identified (11), the transcript of H19 gene has been proposed as a long non-coding RNA (lncRNA). Expression of IncRNA H19 is developmentally regulated, since it is abundantly expressed in extra-embryonic and fetal tissues but significantly repressed in the majority of adult organs following birth. Deregulation of H19 is found in a variety of cancer tissues, but its status and roles in cancer remains controversial. H19 is initially suggested as a suppressor for tumor development and metastasis $(12,13)$. However, previously H19 has been proposed as an oncogenic lncRNA in numerous cancers $(14,15)$, and is found to positively regulate the metastatic potential of cancer cells $(16,17)$. In endometrioid endometrial cancer tissues (18-20), overexpression of H19 exists and is associated with neoplastic cell invasion. However, the precise function of $\mathrm{H} 19$ in cellular processes involved in progression of endometrioid endometrial cancer is not yet understood.

H19 is associated with epithelial-mesenchymal transition (EMT) in certain cancers $(16,17)$, which presents a novel mechanistic insight into the role of H19 in tumor progression. EMT, first described in embryogenesis, is integrated into pathological processes such as organ fibrosis and cancer progression. EMT refers to the process by which epithelial properties, including the compacted morphology and epithelial marker expression, 
are replaced by the mesenchymal phenotype, such as dispersed spindle-shaped morphology and mesenchymal gene expression, accompanied by the enhancement of cell motility and invasion. This provides evidence for EMT having a role in the promotion of the migratory and invasive capabilities of cancer cells. The most studied EMT-associated molecules are E-cadherin, the adherens junction protein in epithelial cells, and its transcriptional repressors, including Snail, Slug, Twist and Zeb. These transcription factors are upregulated during EMT, binding to the E-box in the promoter region of the gene encoding the E-cadherin $(\mathrm{CDH})$, repressing $\mathrm{CDH}$ transcription, and finally leading to the loss of apical-basal polarity and cell-cell adhesion junction.

In the present study, the level of H19 was increased in cancerous tissues compared with paratumoral tissues. Suppression of H19 by small interfering RNA (siRNA) inhibited cell motility and invasion, reduced Snail expression and increased E-cadherin expression, without affecting the vimentin level in HEC-1B endometrial cancer cells, indicating partial reversion of EMT process by $\mathrm{H} 19$ decrease. These results highlighted the pro-tumor role of $\mathrm{H} 19$ in endometrial cancer progression.

\section{Materials and methods}

Tissue specimens. The study included 20 primary adenocarcinomas of endometrioid origin and matched paratumoral normal tissues. Tissue samples were acquired from the Department of Gynecology and Obstetrics at the First Affiliated Hospital of Xi'an Jiaotong University between January 2013 and October 2014. The patients underwent radical hysterectomy with complete clinical history records. All patients received no chemotherapy or radiotherapy prior to surgery. Informed content was obtained from all patients involved, and the study protocol was performed under approval of the Ethics Committee of the First Affiliated Hospital, Xi'an Jiaotong University.

Cell line and culture. The human endometrial cancer cell line HEC-1-B was obtained from the Shanghai Cell Bank of Chinese Academy of Sciences (Shanghai, China). Cells were grown in RPMI 1640 supplemented with 10\% newborn bovine serum (Gibco; Thermo Fisher Scientific, Inc., Waltham, MA, USA) in a humidified atmosphere with $5 \% \mathrm{CO}_{2}$ at $37^{\circ} \mathrm{C}$.

siRNA transfection. Transfection of siRNA was conducted using the X-tremeGENE siRNA transfection reagent (Roche Applied Science, Madison, WI, USA) according to the manufacturer's protocol. siRNAs specific to the human H19 gene were synthesized by Shanghai GenePharma Co., Ltd. (Shanghai, China), and the sequences were as follows siH19-a, 5'-UAAGUCAUUUGCACUGGUUdTdT-3' and siH19-b, 5'-CCAACAUCAAAGACACCAUdTdT-3'. A scrambled siRNA (5'-UUCUCCGAACGUGUCACGUTT-3') was used in parallel experiments as a negative control. Cells were plated onto 6-well plates and grew to $40-50 \%$ confluence at the time of transfection. For each sample, $1 \mu \mathrm{g}$ of the siRNA and $5 \mu \mathrm{l}$ of transfection reagent were incubated in $100 \mu \mathrm{l}$ of serum- and antibiotics- free medium for $5 \mathrm{~min}$, respectively. This was followed by mixing the solutions together and incubating at room temperature for another $20 \mathrm{~min}$, and the resultant solution was layered over cells at $37^{\circ} \mathrm{C}$ for $48 \mathrm{~h}$ for RNA extraction and $72 \mathrm{~h}$ for protein extraction.

RNA isolation and reverse transcription. Isolation of total RNA was performed using TRIzol reagent (Invitrogen; Thermo Fisher Scientific, Inc.), in accordance with the manufacturer's protocol. Quality and concentration of total RNA were assessed using a UV spectrophotometer (Bio-Rad Laboratories, Inc., Hercules, CA, USA) at a 260/280 nm absorbance ratio and at the $260 \mathrm{~nm}$ absorbance, respectively. First strand cDNA was synthesized using RevertAid first strand cDNA synthesis kit (Thermo Fisher Scientific, Inc.), according to the manufacturer's protocol. The reverse transcription reactions were performed at $25^{\circ} \mathrm{C}$ for $5 \mathrm{~min}$, followed by $42^{\circ} \mathrm{C}$ for $60 \mathrm{~min}$ and $70^{\circ} \mathrm{C}$ for $5 \mathrm{~min}$. The cDNAs were stored at $-80^{\circ} \mathrm{C}$ for later use.

Quantitative (q)PCR. qPCR was performed using a CFX-96 qPCR system (Bio-Rad Laboratories, Inc.) and SYBR Green Master Mix (Takara Biotechnology Co. Ltd., Dalian, China). The gene $\beta$-actin was used as an internal control. The PCR reaction mixture was prepared following the manufacturer's protocol for the SYBR ${ }^{\circledR}$ Premix Ex Taq ${ }^{\mathrm{TM}}$ (Takara Biotechnology Co., Ltd., Dalian, China). The temperature cycle profile for the PCR reactions was $95^{\circ} \mathrm{C}$ for $30 \mathrm{sec}$, followed by 40 cycles of $95^{\circ} \mathrm{C}$ for $5 \mathrm{sec}$ and $60^{\circ} \mathrm{C}$ for $30 \mathrm{sec}$. Each measurement was performed in triplicate, and no template controls were included for each assay. Subsequent to PCR, a dissociation curve analysis was performed. The relative quantity of gene expression was calculated automatically by the $2^{-\Delta \Delta \mathrm{Cq}}$ method (21). Primers were synthesized by Shanghai Shenggong Biology Engineering Technology Service, Ltd. (Shanghai, China), as follows: H19 forward, 5'-TGCTGCACT TTACAACCACTG-3' and reverse, 5'-ATGGTGTCTTTG ATGTTGGGC-3'; E-cadherin forward, 5'-GCTGCTCTTGCT GTTTCTTCG-3' and reverse, 5'-CCGCCTCCTTCTTCA TCATAG-3'; vimentin forward, 5'-AAGTTTGCTGACCTC TCTGAGGCT-3' and reverse 5'-CTTCCATTTCACGCATCT GGCGTT-3'; Snail forward, 5'-TCCAGAGTTTACCTTCCA GCA-3' and reverse 5'-CTTTCCCACTGTCCTCATCTG-3'; $\beta$-actin forward, 5'-TCCCTGGAGAAGAGCTACGA-3' and reverse 5'-AGCACTGTGTTGGCGTACAG-3'.

Western blot analysis. Total protein was isolated from cells in RIPA lysis buffer on ice. Protein concentration was determined using Bradford Protein Assay kit (Bio-Rad Laboratories, Inc.). Proteins were boiled, then separated by sodium dodecyl sulfate-polyacrylamide gel electrophoresis and transferred onto nitrocellulose membranes (Pall Life Sciences, Port Washington, NY, USA). The membranes were blocked with $5 \%$ non-fat milk at room temperature for $1 \mathrm{~h}$, incubated with primary antibodies, including monoclonal rabbit-anti human E-cadherin (dilution, 1:1,000; \#3195), monoclonal rabbit-anti human vimentin (dilution, 1:1,000; \#5741), monoclonal rabbit-anti human Snail (dilution, 1:500; \#3879) and monoclonal mouse-anti human $\beta$-actin (dilution, 1:1,000; \#3700) (Cell Signaling Technology, Inc., Danvers, MA, USA) overnight at $4^{\circ} \mathrm{C}$. The membranes were then exposed to horseradish peroxidase (HRP) conjugated goat anti-rabbit immunoglobulin (IgG) (dilution, 1:1,000; \#31460; Pierce Biotechnology, Inc., 
Table I. Clinicopathological parameters of patients with endometrial cancer.

\begin{tabular}{ll}
\hline Clinicopathological parameter & Value, $\%(\mathrm{n})$ \\
\hline Age, years & \\
$<50$ & $65.0(13 / 20)$ \\
$\geq 50$ & $35.0(7 / 20)$ \\
FIGO & \\
I & $70.0(14 / 20)$ \\
II & $15.0(3 / 20)$ \\
III & $15.0(3 / 20)$ \\
Grade & \\
Well differentiated & $25.0(5 / 20)$ \\
Moderately differentiated & $60.0(12 / 20)$ \\
Poorly differentiated & $15.0(3 / 20)$ \\
Invasion depth ${ }^{\mathrm{a}}$ & \\
$<1 / 3$ & $75.0(15 / 20)$ \\
$\geq 1 / 3$ & $25.0(5 / 20)$ \\
Invasion to cervix uterus, ovary or oviduct & \\
No & $80.0(16 / 20)$ \\
Yes & $20.0(4 / 20)$ \\
\hline${ }^{a}$ More or less than one third into the uterine wall. FIGO,international \\
federation of gynecology and obstetrics. \\
\hline
\end{tabular}

Rockford, IL, USA) for detection of E-cadherin, vimentin and Snail, or HRP conjugated goat anti-mouse IgG (dilution, 1:1,000; \#31430; Pierce, Biotechnology, Inc.) for detection of $\beta$-actin. Immunodetection was performed using ECL reagent (Santa Cruz Biotechnology, Santa Cruz, CA, USA) and luminescence image system (Bio-Rad Laboratories, Inc.). The protein amounts were semi-quantified by analyzing blot intensity using $\beta$-actin as loading control. In total, 3 independent experiments were performed.

Cell viability. Cell viability was assessed using Cell Counting kit-8 (CCK-8) (7sea; Pharmatech Co., Ltd., Shanghai, China) assays. The cells were inoculated into 96-well plates, and then transfected with siRNA or negative control, respectively, for 24-96 h. The cells were then incubated with CCK-8 for $4 \mathrm{~h}$ at $37^{\circ} \mathrm{C}$, and absorbance at $450 \mathrm{~nm}$ was determined using an EnSpire multimode plate reader (PerkinElmer, Inc., Waltham, MA, USA).

Wound healing assay. Cells were seeded into 6-well plate and transfected with siRNA specific to H19 or scrambled siRNA control for $24 \mathrm{~h}$. When cells reached $90 \%$ confluence, wounds were generated by scratching the monolayers using a $200 \mu \mathrm{l}$ pipette tip. Cells were washed to remove the detached cells and then maintained in media without serum. Images were captured on an inverted microscope (Leica Biosystems, Wetzlar, Germany) installed with a ToupCam digital camera and ToupView 3.7 software (ToupTek, Hangzhou, China) of the wounded areas following incubation for $72 \mathrm{~h}$.
Table II. Clinicopathological parameters of patients with endometrial cancer according to H19 expression.

\begin{tabular}{llc}
\hline Clinicopathological parameters & H19 level & P-value \\
\hline Age, years & & 0.637 \\
$\quad<50$ & $1.662 \pm 0.475$ & \\
$\geq 50$ & $2.028 \pm 0.494$ & \\
FIGO & & 0.374 \\
I & $1.790 \pm 0.384$ & \\
II & $1.271 \pm 0.272$ & \\
III & $3.041 \pm 1.613$ & \\
Grade & & 0.014 \\
Well differentiated & $0.965 \pm 0.229$ & \\
Moderately differentiated & $1.742 \pm 0.291$ & \\
Poorly differentiated & $4.092 \pm 1.676$ & \\
Invasion depth & & \\
$\quad<1 / 3$ & & 0.192 \\
$\geq 1 / 3$ & $1.627 \pm 0.359$ & \\
Invasion to cervix uterus, & $2.718 \pm 0.911$ & \\
ovary or oviduct & & 0.427 \\
Negative & & \\
Positive & $1.754 \pm 0.336$ & \\
\hline
\end{tabular}

${ }^{a}$ More or less than one third into the uterine wall. FIGO, international federation of gynecology and obstetrics.

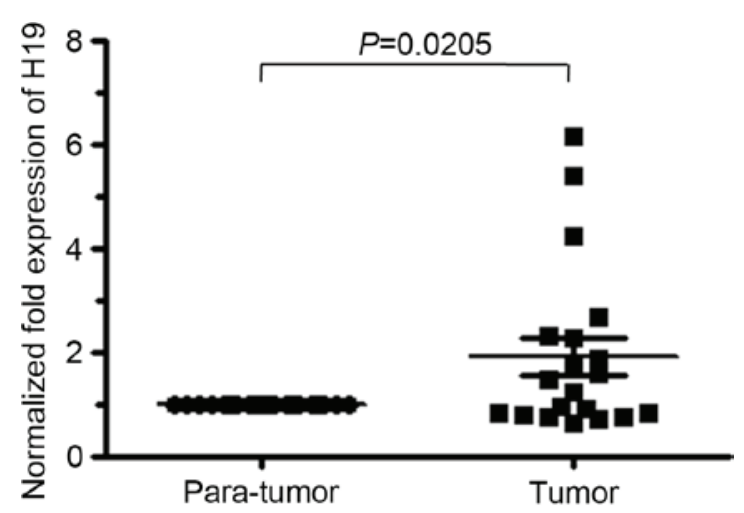

Figure 1. H19 mRNA in endometrial cancer and para-cancer tissues. Total RNA was extracted from tissues and quantitative polymerase chain reaction was used to detect the H19 mRNA level. H19 mRNA level in cancer tissues was almost 2 -fold of that in paratumoral tissues. $\mathrm{P}<0.05$ was considered to indicate a statistically significant difference.

Transmigration and invasion assays. Cellular migration and invasion were tested using Millicell modified Boyden chambers (EMD Millipore, Billerica, MA, USA) with (invasion assay) or without (migration assay) Matrigel-coated membrane. Cells were seeded in serum-free medium into the upper chamber and allowed to migrate or invade toward media containing $20 \%$ fetal bovine serum (FBS) as a chemoattractant in the lower chamber for $24 \mathrm{~h}$ (migration assay) or $48 \mathrm{~h}$ (invasion assay). Cells on the upper surface of the membrane were removed with a cotton swab, and cells at the bottom of the membrane were fixed with $5 \%$ glutaric dialdehyde 
A

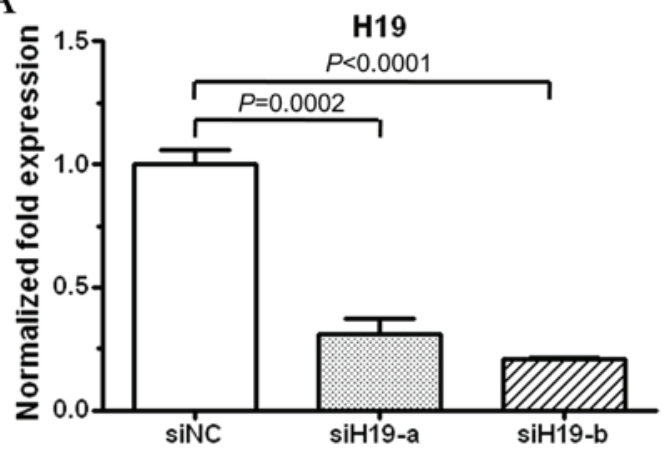

B

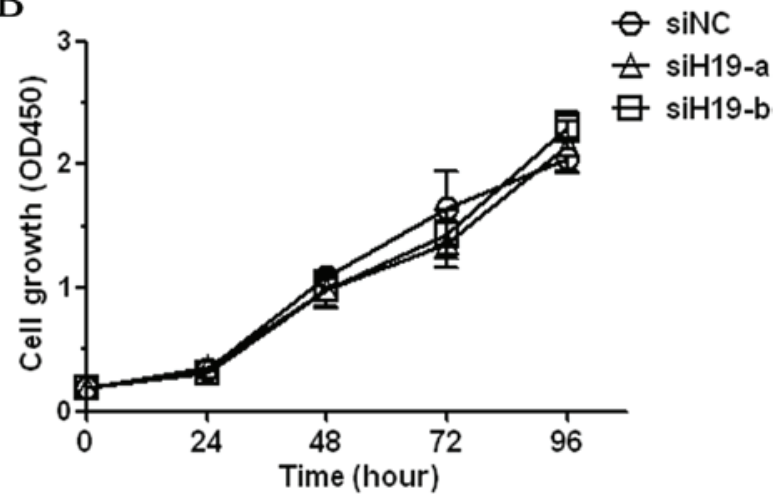

Figure 2. H19 inhibition had no effect on proliferation of HEC-1-B endometrial cancer cells. (A) Examination of efficacy of H19 siRNAs. HEC-1-B cells were transfected for $48 \mathrm{~h}$ with siRNAs specific to H19 (siH19-a and siH19-b) or scrambled control siRNA (siNC), and mRNA level of H19 was determined. Quantitative polymerase chain reaction results showed that siH19-a and siH19-b may effectively knock down H19 mRNA level. (B) Cell Counting Kit 8 assay was used to assess the effect of H19 downregulation on growth of HEC-1-B cells in vitro. Compared to negative control cells, H19-suppressed cells showed no inhibition of cell growth. Results represent the mean of 3 independent experiments performed in triplicate. siRNA, small interfering RNA.

and stained with Giemsa (Sigma-Aldrich; Merck Millipore, Darmstadt, Germany). The number of transmigrated cells was counted in 5 random fields under an inverted microscope (Leica Biosystems) installed with the ToupCam digital camera and ToupView software (ToupTek) (magnification, x200). Each experiment was performed in triplicate.

Statistical analysis. Statistical differences were determined by Student's two-tailed $t$-test. All statistical analyses were conducted using SPSS statistical software (SPSS, Inc., Chicago, IL, USA). Values were considered to indicate a statistically significant difference at $\mathrm{P}<0.05$ and highly significant difference at $\mathrm{P}<0.01$.

\section{Results}

Expression of $\mathrm{H} 19$ in endometrial cancer and paratumoral tissues. In total, 20 informative cases were analyzed. The ages of the patients ranged between 38 and 70 years (median age, 54 years). The clinicopathological characteristics of the patients were summarized in Table I. The average level for H19 RNA in endometrial cancer was almost 2 -fold that of paratumoral tissues (Fig. 1), and the differential H19 expression status between paratumoral and tumor tissues was statistically significant $(\mathrm{P}=0.0205)$. The H19 transcript level increased with the lack of cellular differentiation. However, no significant association was identified between H19 level and other clinicopathological parameters of endometrial cancer patients ( $P>0.05$; Table II).

Downregulation of $H 19$ exerts no effect on cell viability. To elucidate the roles of $\mathrm{H} 19$ in endometrial cancer progression, HEC-1-B cells were transduced with siRNAs specific to H19 (siH19-a and siH19-b). As determined by qPCR analysis, siH19-a and siH19-b could effectively knockdown H19 level (Fig. 2A). The effect of H19 under-expression on cell viability was subsequently examined, and the results showed that the viability of H19-suppressed cells was almost the same as negative control cells during $96 \mathrm{~h}$ of siRNA transfection (Fig. 2B). These results showed that H19 overexpression did not confer proliferation advantage on HEC-1-B cells.
Suppression of H19 inhibits cell migration and invasion ability. The present study examined the effect of H19 suppression on cell mobility with a wound-healing assay. As shown in Fig. 3A, downregulation of H19 impeded wound closure of HEC-1-B cells over 72 h of H19 siRNA transfection. Transmigration and invasion assays additionally showed that H19 under-expression significantly lessened the in vitro migration and invasion ability of HEC-1-B cells (Fig. 3B). These results indicated $\mathrm{H} 19$ was involved in the metastatic spread of endometrial cancer cell.

Knockdown of $H 19$ partially reverses the EMT process. To explore the possible mechanism of $\mathrm{H} 19$ in cancer cell migration and invasion, occurrence of EMT was examined by detecting the expression changes of EMT molecules. Knocking-down of H19 increased E-cadherin mRNA and protein, but caused no evident change in vimentin expression (Fig. 4A). Increase of E-cadherin mRNA indicated H19 suppression may release transcription of E-Cadherin coding gene from repression. Expression of E-cadherin transcription repressor Snail was then examined in H19-suppressed cells, and reduction of Snail at mRNA and protein level was observed (Fig. 4B). These results suggested $\mathrm{H} 19$ decrease resulted in a partial reverse of EMT.

\section{Discussion}

Relative survival for endometrial cancer has not substantially improved over past decades $(22,23)$. It is necessary to mechanistically study endometrial cancer progression and identify novel markers to monitor disease progression or to develop gene-oriented drugs. The H19 gene is transcribed in a long non-coding RNA molecule that accumulates in fetal tissues but is repressed in the majority of adult organs (24). Dysregulation of $\mathrm{H} 19$ is associated with cancer, but inconsistency exists about the role of $\mathrm{H} 19$ in tumor development and progression (25-27). The observations in certain cancers support an oncogenic role of $\mathrm{H} 19$, since it is overexpressed and regulates genes involved in tumor growth, metastasis and angiogenesis $(15,24,28,29)$. However, in other cases, H19 was not considered an oncodevelopmental 
A

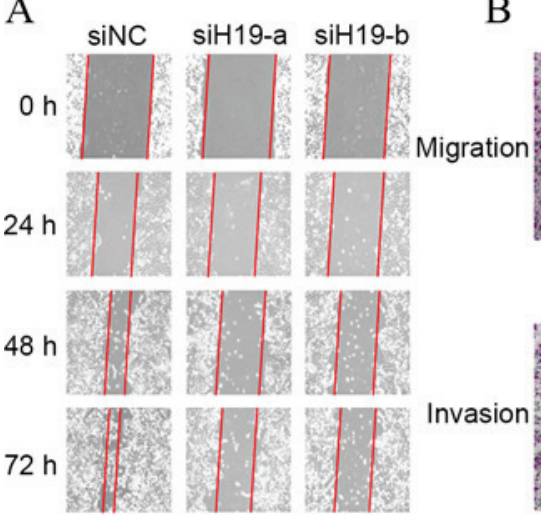

B

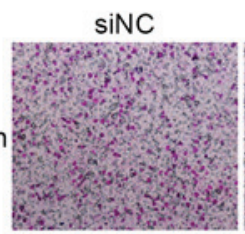

$\mathrm{siH} 19-\mathrm{a}$
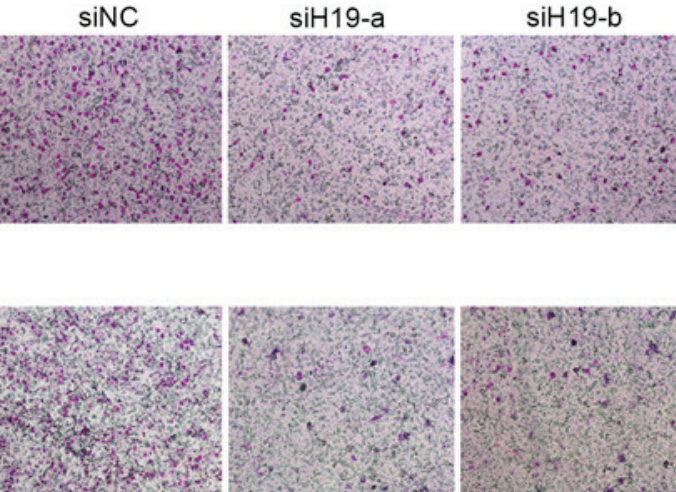

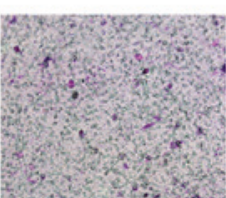

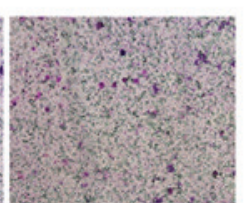

$(\times 100)$
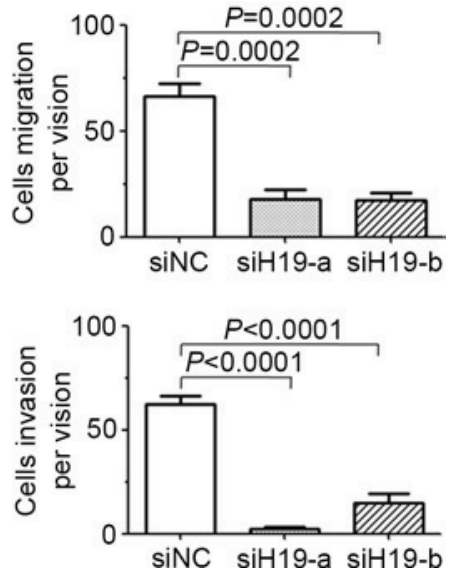

Figure 3. Knockdown of H19 reduced migration and invasion of HEC-1-B cells. (A) Cell mobility was detected by wound healing assay. HEC-1-B cells were transfected with siRNAs for $24 \mathrm{~h}$ followed by being scratched. The closure of the scratch was monitored for the indicated time periods and images were captured (magnification, x100). Compared with negative control cells, inhibition of H19 significantly slowed the closure of the scratch. (B) Cellular migration and invasion were examined by in vitro migration and invasion assays. Cells transfected with siRNAs for $24 \mathrm{~h}$ were seeded into millicells with (invasion assay) or without Matrigel-coated membrane (migration assay), followed by incubation for $24 \mathrm{~h}$. The number of cells that passed through the membrane per field of view under x10 magnification were counted and used to represent the migration or invasion capacities of cells. Transfection of H19 siRNAs into HEC-1-B cells substantially reduced cell migration and invasion. All treatments in this figure were performed in triplicate, and the results are shown as the means \pm standard deviation. $\mathrm{P}<0.05$ was considered to indicate a statistically significant difference. siRNA, small interfering RNA.

A

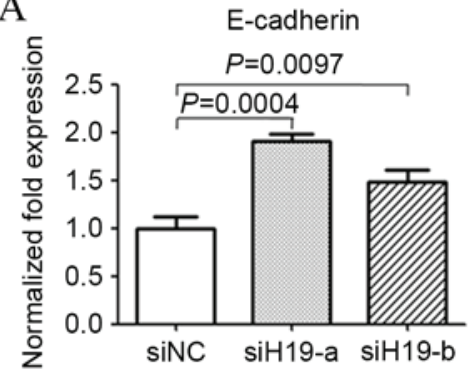

B

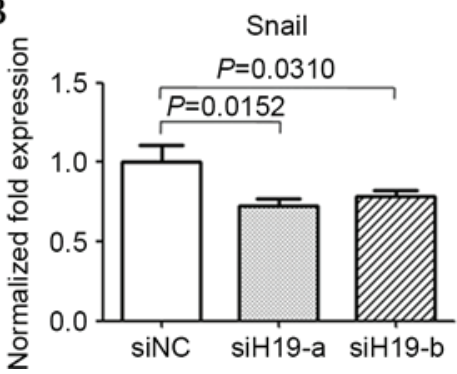

Vimentin

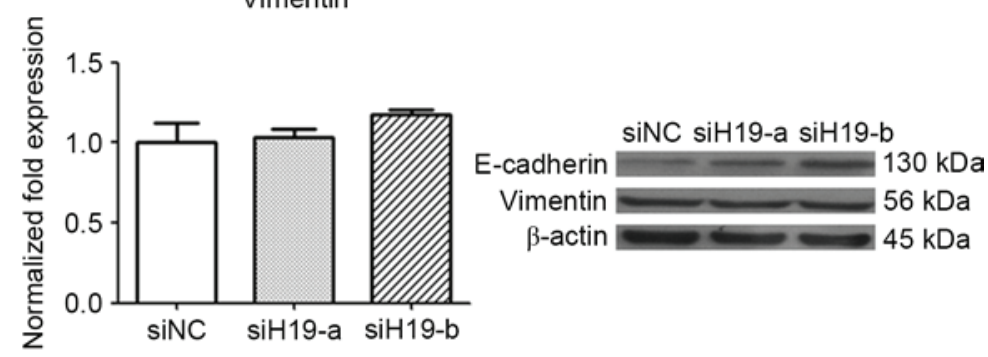

siNC siH19-a siH19-b

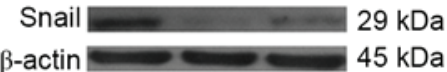

Figure 4. H19 suppression changed expression level of epithelial-mesenchymal transition molecules in HEC-1-B cells. (A) The expression level of E-cadherin and vimentin in cells exposed to siNC, siH19-a or siH19-b was monitored by quantitative polymerase chain reaction and western blot analysis, with $\beta$-actin as an internal control. Knockdown of H19 increased E-cadherin at the mRNA level and protein level, but caused no evident change in vimentin expression. (B) Subsequent to H19 small interfering RNA transfection, mRNA and protein levels of Snail were examined, and standardized against the level present in negative control cells using $\beta$-actin as a loading control. H19 suppression significantly decreased Snail expression level in HEC-1-B cells. All treatments in this fig. were performed in triplicate, and values are presented as the mean \pm standard deviation of the three experiments. P<0.05 was considered significantly different for $t$-test. siNC, small interfering negative control, siH19, small interfering RNA specific to H19.

marker $(13,30)$. At present, the function of H19 in endometrial cancer invasion has not been well established. In the present study, overexpressed H19 was found to be associated with EMT in endometrial cancer, without conferring a growth advantage on endometrial cancer cells. This supports the conclusion that $\mathrm{H} 19$ is actively linked with cell aggressiveness and positively effects the progression of endometrial cancer.

Several lines of evidence have been presented for the reasons why $\mathrm{H} 19$ is dysregulated in adult cancer tissues $(15,16,31,32)$. H19 is responsive to the induction of pro-tumor factors in the cancer microenvironment including transforming growth factor- $\beta$ and hypoxia (16). In addition, $\mathrm{H} 19$ is under the control of promoter regulation. It has been reported that the $\mathrm{H} 19$ promoter is activated by oncogenic transcription factors such as c-myc (31), but negatively modulated by the tumor suppressor p53 (33). Methylation in the promoter region is another regulatory mechanism of H19 expression. In ovarian cancer cells, overexpression of histone $\mathrm{H} 1$ variant 
H1.3 increases occupancy of H1.3 at the H19 regulator region, leading to increase of DNA methylation and H19 knockdown (15). Additional investigation is required to determine whether similar regulatory mechanisms for $\mathrm{H} 19$ expression exist in endometrial cancer.

The importance of EMT has been well documented in cancer metastasis; however, published literature about the implication of H19 in EMT is inconsistent. H19 promotes EMT via antagonizing let-7 and contributing to HMGA2-mediated EMT in pancreatic ductal adenocarcinoma (17), or by being associated with enhancer of zeste homolog 2 (EZH2) and activating wingless $/ \beta$-catenin to decrease E-cadherin in bladder cancer (34). H19 has been identified to encode microRNA-675 (miR-675), and a positive feedback loop between H19/miR-675 and Slug has been reported to attenuate E-cadherin and lead to EMT in certain cancer cell lines (16). However, H19 is found to reverse EMT by activating the miR-200 family in hepatocellular carcinoma (35). In addition, overexpressed miR-675 downregulates Twist1 and reverses EMT in AFP-secreting hepatocellular carcinoma (30). Furthermore, no effect of H19 reduction on proliferation is observed in endometrial cancer cells. Although certain published studies have shown that H19 affects cancer cell proliferation (36,37), it also has been found that H19 RNA has conferred growth advantage for the cells when cultured in serum-poor medium rather than in 10\% FBS, partly due to the inability of the $\mathrm{H} 19$-expressing cells to induce the cyclin-dependent kinase inhibitor p57 (kip2) in response to serum stress (38). Therefore, the tumor microenvironment or cell type may determine the expression and the role of H19 in cancer. It is necessary to verify the cellular evidence in the in vivo systems.

In summary, the present study provides key molecular insights into endometrial cancer biology and a possibility for gene-oriented drug development. Nevertheless, the detailed mechanism merits additional investigation to contribute to a decrease in endometrial cancer mortality.

\section{References}

1. Ferlay J, Soerjomataram I, Dikshit R, Eser S, Mathers C, Rebelo M, Parkin DM, Forman D and Bray F: Cancer incidence and mortality worldwide: Sources, methods and major patterns in GLOBOCAN 2012. Int J Cancer 136: E359-E386, 2015.

2. Weiderpass E, Antoine J, Bray FI, Oh JK and Arbyn M: Trends in corpus uteri cancer mortality in member states of the European Union. Eur J Cancer 50: 1675-1684, 2014.

3. Duong LM, Wilson RJ, Ajani UA, Singh SD and Eheman CR: Trends in endometrial cancer incidence rates in the United States, 1999-2006. J Womens Health (Larchmt) 20: 1157-1163, 2011.

4. Edwards BK, Noone AM, Mariotto AB, Simard EP, Boscoe FP Henley SJ, Jemal A, Cho H, Anderson RN, Kohler BA, et al: Annual Report to the Nation on the status of cancer, 1975-2010, featuring prevalence of comorbidity and impact on survival among persons with lung, colorectal, breast, or prostate cancer. Cancer 120: 1290-1314, 2014.

5. Li X, Zheng S, Chen S, Qin F, Lau S and Chen Q: Trends in gynaecological cancers in the largest obstetrics and gynaecology hospital in China from 2003 to 2013. Tumour Biol 36: 4961-4966, 2015.

6. Bansal N, Yendluri V and Wenham RM: The molecular biology of endometrial cancers and the implications for pathogenesis, classification and targeted therapies. Cancer Control 16: 8-13, 2009.

7. Bokhman JV: Two pathogenetic types of endometrial carcinoma. Gynecol Oncol 15: 10-17, 1983.
8. Setiawan VW, Yang HP, Pike MC, McCann SE, Yu H, Xiang YB, Wolk A, Wentzensen N, Weiss NS, Webb PM, et al: Type I and II endometrial cancers: Have they different risk factors? J Clin Oncol 31: 2607-2618, 2013.

9. Zemel S, Bartolomei MS and Tilghman SM: Physical linkage of two mammalian imprinted genes, H19 and insulin-like growth factor 2. Nat Genet 2: 61-65, 1992.

10. Zhang Y and Tycko B: Monoallelic expression of the human H19 gene. Nat Genet 1: 40-44, 1992.

11. Pachnis V, Brannan CI and Tilghman SM: The structure and expression of a novel gene activated in early mouse embryogenesis. EMBO J 7: 673-681, 1988.

12. Hao Y, Crenshaw T, Moulton T, Newcomb E and Tycko B: Tumour-suppressor activity of H19 RNA. Nature 365: 764-767, 1993.

13. Zhu M, Chen Q, Liu X, Sun Q, Zhao X, Deng R, Wang Y, Huang J, Xu M, Yan J and Yu J: lncRNA H19/miR-675 axis represses prostate cancer metastasis by targeting TGFBI. FEBS J 281: 3766-3775, 2014.

14. Berteaux N, Lottin S, Monté D, Pinte S, Quatannens B, Coll J, Hondermarck H, Curgy JJ, Dugimont T and Adriaenssens E: H19 mRNA-like noncoding RNA promotes breast cancer cell proliferation through positive control by E2F1. J Biol Chem 280: 29625-29636, 2005.

15. Medrzycki M, Zhang Y, Zhang W, Cao K, Pan C, Lailler N, McDonald JF, Bouhassira EE and Fan Y: Histone h1.3 suppresses h19 noncoding RNA expression and cell growth of ovarian cancer cells. Cancer Res 74: 6463-6473, 2014.

16. Matouk IJ, Raveh E, Abu-lail R, Mezan S, Gilon M, Gershtain E, Birman T, Gallula J, Schneider T, Barkali M, et al: Oncofetal H19 RNA promotes tumor metastasis. Biochim Biophys Acta 1843: 1414-1426, 2014.

17. Ma C, Nong K, Zhu H, Wang W, Huang X, Yuan Z and Ai K: H19 promotes pancreatic cancer metastasis by derepressing let-7's suppression on its target HMGA2-mediated EMT. Tumour Biol 35: 9163-9169, 2014.

18. Tanos V, Ariel I, Prus D, De-Groot N and Hochberg A: H19 and IGF2 gene expression in human normal, hyperplastic and malignant endometrium. Int J Gynecol Cancer 14: 521-525, 2004.

19. Lottin S, Adriaenssens E, Berteaux N, Lepretrê A, Vilain MO, Denhez E, Coll J, Dugimont T and Curgy JJ: The human H19 gene is frequently overexpressed in myometrium and stroma during pathological endometrial proliferative events. Eur J Cancer 41: 168-177, 2005.

20. Mokhtar NM, Ramzi NH, Yin-Ling W, Rose IM, Hatta Mohd Dali AZ and Jamal R: Laser capture microdissection with genome-wide expression profiling displayed gene expression signatures in endometrioid endometrial cancer. Cancer Invest 30: 156-164, 2012.

21. Livak KJ and Schmittgen TD: Analysis of relative gene expression data using real-time quantitative PCR and the 2(-Delta Delta C(T)) Method. Methods 25: 402-408, 2001.

22. Siegel RL, Miller KD and Jemal A: Cancer statistics, 2015. CA Cancer J Clin 65: 5-29, 2015.

23. Chen W, Zheng R, Baade PD, Zhang S, Zeng H, Bray F, Jemal A, Yu XQ and He J: Cancer statistics in China, 2015. CA Cancer J Clin 66: 115-132, 2016.

24. Matouk IJ, DeGroot N, Mezan S, Ayesh S, Abu-lail R, Hochberg A and Galun E: The H19 non-coding RNA is essential for human tumor growth. PloS one 2: e845, 2007.

25. Wang L, Sun Y, Yi J, Wang X, Liang J, Pan Z, Li L and Jiang G: Targeting H19 by lentivirus-mediated RNA interference increases A549 cell migration and invasion. Exp Lung Res 1-8, 2016. (Epub ahead of print)

26. Zhang E, Li W, Yin D, De W, Zhu L, Sun S and Han L: c-Myc-regulated long non-coding RNA H19 indicates a poor prognosis and affects cell proliferation in non-small-cell lung cancer. Tumour Biol 37: 4007-4015, 2016.

27. Yoshimizu T, Miroglio A, Ripoche MA, Gabory A, Vernucci M, Riccio A, Colnot S, Godard C, Terris B, Jammes H and Dandolo L: The H19 locus acts in vivo as a tumor suppressor. Proc Natl Acad Sci USA 105: 12417-12422, 2008.

28. Wang L, Cai Y, Zhao X, Jia X, Zhang J, Liu J, Zhen H, Wang T, Tang X, Liu Y and Wang J: Down-regulated long non-coding RNA H19 inhibits carcinogenesis of renal cell carcinoma. Neoplasma 62: 412-418, 2015.

29. Xia T, Liao Q, Jiang X, Shao Y, Xiao B, Xi Y and Guo J: Long noncoding RNA associated-competing endogenous RNAs in gastric cancer. Sci Rep 4: 6088, 2014. 
30. Hernandez JM, Elahi A, Clark CW, Wang J, Humphries LA, Centeno B, Bloom G, Fuchs BC, Yeatman T and Shibata D: miR-675 mediates downregulation of Twist1 and $\mathrm{Rb}$ in AFP-secreting hepatocellular carcinoma. Ann Surg Oncol (20 Suppl 3): S625-S635, 2013.

31. Guo G, Kang Q, Chen Q, Chen Z, Wang J, Tan L and Chen JL: High expression of long non-coding RNA H19 is required for efficient tumorigenesis induced by Bcr-Abl oncogene. FEBS Lett 588: 1780-1786, 2014.

32. Min HY, Lee SC, Woo JK, Jung HJ, Park KH, Jeong HM, Hyun SY, Cho J, Lee W, Park JE, et al: Essential role of DNA methyltransferase 1-mediated transcription of insulin-like growth factor 2 in resistance to histone deacetylase inhibitors. Clin Cancer Res pii: clincanres.0534.2016, 2016. (Epub ahead of print)

33. Dugimont T, Montpellier C, Adriaenssens E, Lottin S, Dumont L, Iotsova V, Lagrou C, Stéhelin D, Coll J and Curgy JJ: The H19 TATA-less promoter is efficiently repressed by wild-type tumor suppressor gene product p53. Oncogene 16: 2395-2401, 1998.
34. Luo M, Li Z, Wang W, Zeng Y, Liu Z and Qiu J: Long non-coding RNA H19 increases bladder cancer metastasis by associating with EZH2 and inhibiting E-cadherin expression. Cancer Lett 333: 213-221, 2013.

35. Zhang L, Yang F, Yuan JH, Yuan SX, Zhou WP, Huo XS, $\mathrm{Xu} \mathrm{D}, \mathrm{Bi} \mathrm{HS}$, Wang $\mathrm{F}$ and Sun SH: Epigenetic activation of the MiR-200 family contributes to H19-mediated metastasis suppression in hepatocellular carcinoma. Carcinogenesis 34 : 577-586, 2013.

36. Zhang EB, Han L, Yin DD, Kong R, De W and Chen J: c-Myc-induced, long, noncoding $\mathrm{H} 19$ affects cell proliferation and predicts a poor prognosis in patients with gastric cancer. Med Oncol 31: 914, 2014

37. Yang F, Bi J, Xue X, Zheng L, Zhi K, Hua J and Fang G: Up-regulated long non-coding RNA H19 contributes to proliferation of gastric cancer cells. FEBS J 279: 3159-3165, 2012.

38. Ayesh S, Matouk I, Schneider T, Ohana P, Laster M, Al-Sharef W, De-Groot N and Hochberg A: Possible physiological role of H19 RNA. Mol Carcinog 35: 63-74, 2002. 